\title{
Promoter activity of Merkel cell Polyomavirus variants in human dermal fibroblasts and a Merkel cell carcinoma cell line
}

Ibrahim Abdulsalam ${ }^{1,2}$, Kashif Rasheed ${ }^{1}$, Baldur Sveinbjørnsson ${ }^{1}$, Bernhard Ehlers ${ }^{3}$ and Ugo Moens ${ }^{1 *}$

\begin{abstract}
Background: Merkel cell polyomavirus (MCPyV) is a human polyomavirus that establishes a life-long harmless infection in most individuals, with dermal fibroblasts believed to be the natural host cell. However, this virus is the major cause of Merkel cell carcinoma (MCC), an aggressive skin cancer. Several MCPyV variants with polymorphism in their promoter region have been isolated, but it is not known whether these differences affect the biological properties of the virus.
\end{abstract}

Methods: Using transient transfection studies in human dermal fibroblasts and the MCC cell line MCC13, we compared the transcription activity of the early and late promoters of the most commonly described non-coding control region MCPyV variant and six other isolates containing specific mutation patterns.

Results: Both the early and late promoters were significantly stronger in human dermal fibroblasts compared with MCC13 cells, and a different promoter strength between the MCPyV variants was observed. The expression of fulllength large T-antigen, a viral protein that regulates early and late promoter activity, inhibited early and late promoter activities in both cell lines. Nonetheless, a truncated large T-antigen, which is expressed in virus-positive MCCs, stimulated the activity of its cognate promoter.

Conclusion: The promoter activities of all MCPyV variants tested was stronger in human dermal fibroblasts, a cell line that supports viral replication, than in MCC13 cells, which are not permissive for MCPyV. Truncated large Tantigen, but not full-length large T-antigen stimulated viral promoter activity. Whether, the difference in promoter strength and regulation by large T-antigen may affect the replication and tumorigenic properties of the virus remains to be determined.

Keywords: Non-coding control region, Large T-antigen, Luciferase assay, MCC13 cells, MCPyV, Mutations

\footnotetext{
* Correspondence: ugo.moens@uit.no

${ }^{1}$ Molecular Inflammation Research Group, Department of Medical Biology, Faculty of Health Sciences, University of Tromsø, The Arctic University of Norway, Tromsø, Norway

Full list of author information is available at the end of the article
}

(C) The Author(s). 2020 Open Access This article is licensed under a Creative Commons Attribution 4.0 International License, which permits use, sharing, adaptation, distribution and reproduction in any medium or format, as long as you give appropriate credit to the original author(s) and the source, provide a link to the Creative Commons licence, and indicate if changes were made. The images or other third party material in this article are included in the article's Creative Commons licence, unless indicated otherwise in a credit line to the material. If material is not included in the article's Creative Commons licence and your intended use is not permitted by statutory regulation or exceeds the permitted use, you will need to obtain permission directly from the copyright holder. To view a copy of this licence, visit http://creativecommons.org/licenses/by/4.0/. The Creative Commons Public Domain Dedication waiver (http://creativecommons.org/publicdomain/zero/1.0/) applies to the data made available in this article, unless otherwise stated in a credit line to the data. 


\section{Background}

In 2008, a new human polyomavirus was isolated, which rekindled the field of polyomavirus research [1]. This virus was isolated from Merkel cell carcinoma (MCC), a rare but aggressive skin cancer. Accordingly, this virus was named Merkel cell polyomavirus (MCPyV). The original study showed that 8 out of the 10 examined MCC samples contained MCPyV DNA [1]. Numerous studies by different groups worldwide have confirmed that approximately $80 \%$ of MCCs are positive for this virus [2-5]. Because cell culture and transgenic mice studies have shown that MCPyV has an oncogenic potential that can be attributed to its viral proteins large T-antigen (LT) and small t-antigen (sT) ([69]), and the association of the virus with MCC, MCPyV is considered an etiological factor in MCC and is classified as probably carcinogenic to humans [10]. Two hallmarks of MCPyV-positive MCCs are the integration of the viral genome in the host chromosome and expression of a truncated version of $\operatorname{LT}[5,11]$. Integration disrupts the late region so that no infectious particles are generated in MCCs, while the truncation of LT results in a non-DNA binding variant that retains the ability to bind the tumor suppressor retinoblastoma protein, but not p53 [12].

Serological studies demonstrated that seroprevalence against $\mathrm{MCPyV}$ increases with age, and reaches up to $\sim 80 \%$ in healthy individuals [13-18]. Little is known about the route of infection, transmission and the cell tropism of MCPyV. Dermal fibroblasts are a genuine host cell for MCPyV [19], and the virus seems to persist in the skin [20-22]. However, PCRbased analyses detected MCPyV DNA in other sites in the body, both in healthy individuals and patients (Supplementary Table S1), as well as in sewage water and environmental surfaces (Supplementary Table S2). The implication of MCPyV in cancers other than $\mathrm{MCC}$ remains unknown, although viral DNA, RNA and proteins can be detected in some cases of other malignancies [23]. Sequence analysis of the MCPyV LT, sT and VP1 genes of different virus isolates revealed genetic variability, but the biological implications in the viral life cycle and the development of MCC have not been studied.

Mutations in the non-coding control region (NCCR) of human polyomaviruses like BKPyV, JCPyV, KIPyV, HPyV7, HPyV9 and HPyV12 have an impact on the transcriptional activity of the promoter, and may affect the virulence of the virus [24-33]. Whether changes in the NCCR of MCPyV have an effect on the promoter activity, and have pathogenic consequences, has not been investigated. Here, we compare the transcriptional activity of NCCR of different MCPyV variants isolated from virus-positive MCC and non-MCC samples in a MCC cell line, and in human dermal fibroblasts.

\section{Methods}

\section{Cells}

The MCPyV-negative MCC13 cell line was kindly provided by Dr. Baki Akgül (University of Cologne, Germany) and was grown in RPMI-1640 (Sigma Life Science, St. Louis, MO. USA; cat. no. R8758) with $10 \%$ fetal bovine serum (Gibco, Life Technologies Limited, Pailey, UK) in the presence of $100 \mu \mathrm{g} / \mathrm{ml}$ streptomycin and 100 units $/ \mathrm{ml}$ penicillin. Immortalized human dermal fibroblasts fHDF/ TERT166 were purchased from Evercyte (Vienna, Austria) and kept in DMEM/Ham's F12 (1:1) (Biochrom, Berlin, Germany; cat. no. F4815), 10\% fetal bovine serum, $2 \mathrm{mM}$ GlutaMaxTM-I (Giboco; cat. no. 35050-038) and $100 \mu \mathrm{g} /$ ml G418 (Santa Cruz Biotechnology, Dallas, TX, USA; cat. no. sc-29,065). Cells were kept in a humidified $\mathrm{CO}_{2}$ incubator at $37^{\circ} \mathrm{C}$.

\section{Plasmids}

The luciferase reporter plasmids with the consensus NCCR $\mathrm{MCPyV}$ in early (pGL3-cons-E) or late (pGL3-cons-L) orientation have been previously described [24]. The luciferase reporter plasmids containing the NCCR of the variants $10 \mathrm{~b}, 15 \mathrm{a}, 16 \mathrm{~b}, \mathrm{HUN}, \mathrm{MKL}-1, \mathrm{MS}-1$ were generated by GenScript (Piscataway, NJ, USA). Each NCCR was cloned in both early (NCCR-E) and late (NCCR-L) orientation, respectively. The luciferase plasmids with the NCCR containing the $25 \mathrm{bp}$ duplication described by Hasida et al. [34] was generated by site-directed mutagenesis using the plasmid pGL3-cons-E (pGL3-cons-L, respectively) containing the consensus NCCR and the complementary primers $5^{\prime}$ GGCCGGAGGCTTTTTTTTCTCTTACAAAGGGAGGAGGACATTTCTCTTACAAAGGG-3' and 5'CCCTTTGTAAGAGAAATGTCCTCCTCCСТT

TGTAAGAGAAAAAAAAGCCTCCGGCC-3'. The empty expression vector pcDNA3.1(+) was purchased from Invitrogen (ThermoFisher Scientific, Oslo, Norway). The MCPyV expression vectors for full-length and truncated LT have been previously described [35], and all plasmids were verified by sequencing. Expression of full-length and truncated LT was confirmed by western blotting using antibody CM2B4 from Santa Cruz Biotechnology (Dallas, TX, USA; cat. no. sc-136,172; results not shown).

\section{Transfection and luciferase assay}

Cells were seeded out in 12-well culture plates. At the time of transfection, the cells were approximately $70 \%$ confluent, with a total of $1 \mu \mathrm{g}$ luciferase reporter plasmid DNA used per well and polyethylenimine (PEI linear MW25000; transfection grade, cat. no. 23966-1, Polysciences, Warrington, PA, USA). DNA was mixed with $150 \mathrm{mM} \mathrm{NaCl}$, and a mixture of PEI: $150 \mathrm{mM} \mathrm{NaCl}$ was then added to the DNA. The ratio DNA:PEI used was 1: 2. This mixture was incubated for $15 \mathrm{~min}$ at room temperature, and then carefully added to the cells. The medium containing the transfection mixture was replaced $4 \mathrm{~h}$ later. Cells were harvested $24 \mathrm{~h}$ after transfection in a $100 \mu \mathrm{l}$ Tropix lysis buffer per well with $0.5 \mathrm{mM}$ DTT freshly added. Cells were centrifuged for $3 \mathrm{~min}$ at 
$12,000 \mathrm{~g}$, and the supernatant was then transferred to a fresh tube. As previously described, $20 \mu$ of supernatant was used in the luciferase assay [35]. Each experiment was repeated at least 3 times, with three independent parallels for each experiment. Luciferase values for each sample were corrected for total protein concentration as determined with the $\mathrm{MN}$ protein quantification assay described by the producer (Macherey-Nagel GmbH, Düren, Germany). We corrected luciferase values by measuring the protein concentration in the corresponding sample rather than co-transfection with a Renilla reporter plasmid to avoid promoter interference between the MCPyV NCCR directing expression of the firefly luciferase gene and a promoter controlling expression of the Renilla luciferase gene. In addition, many of our transfection studies include co-transfection with LT expression plasmids, containing the strong competing CMV promoter. Moreover, LT of polyomaviruses have shown activate many promoters, including the SV40 promoter or the herpes simplex virus thymidine kinase promoter [36], which are commonly used in Renilla reporter plasmids.

\section{Statistics}

A two-tailed Student's $t$-test was used to determine statistical differences between the $\mathrm{MCPyV}$ promoter variants.

\section{Results}

The known MCPyV NCCRs can be classified in six different groups

A comparison of all available complete NCCR sequences of $\mathrm{MCPyV}$ variants revealed a predominant sequence, which is hereafter referred to as the consensus sequence shown in Fig. 1. Based on this consensus sequence, we classified the different NCCR variants in seven groups (Fig. 1 and Table 1). Group 1 contains the MCPyV strains with a consensus or quasi consensus (i.e. one or few point mutations). Group 2 contains NCCR variants with an insertion of the AAC or AACTC sequence at nucleotide 369 (numbering according to the consensus sequence). Group 3 NCCR has an insertion of the TCAAT sequence at nucleotide 372 , while group 4 has deletion of the CCTTAGAT sequence (nucleotides 105112). Group 5 has both an insertion (ACAA or ACAAC at nucleotide 372) and a deletion of nucleotides 381-387 (AACAAGG). The NCCR in group 6 has three insertions: CAAC after nucleotide 373 , T after nucleotide 379 and AA after nucleotide 383. Lastly, group 7 variants have a 25 bp duplication.

The biological source of each NCCR variant is given in Table 1 and Supplementary Table S1. Consensus NCCRs are found in strains present in non-diseased and diseases tissue/individuals. Likewise, NCCR variants circulate in healthy individuals and patients. MCPyV variants with consensus and mutated NCCRs have been isolated from

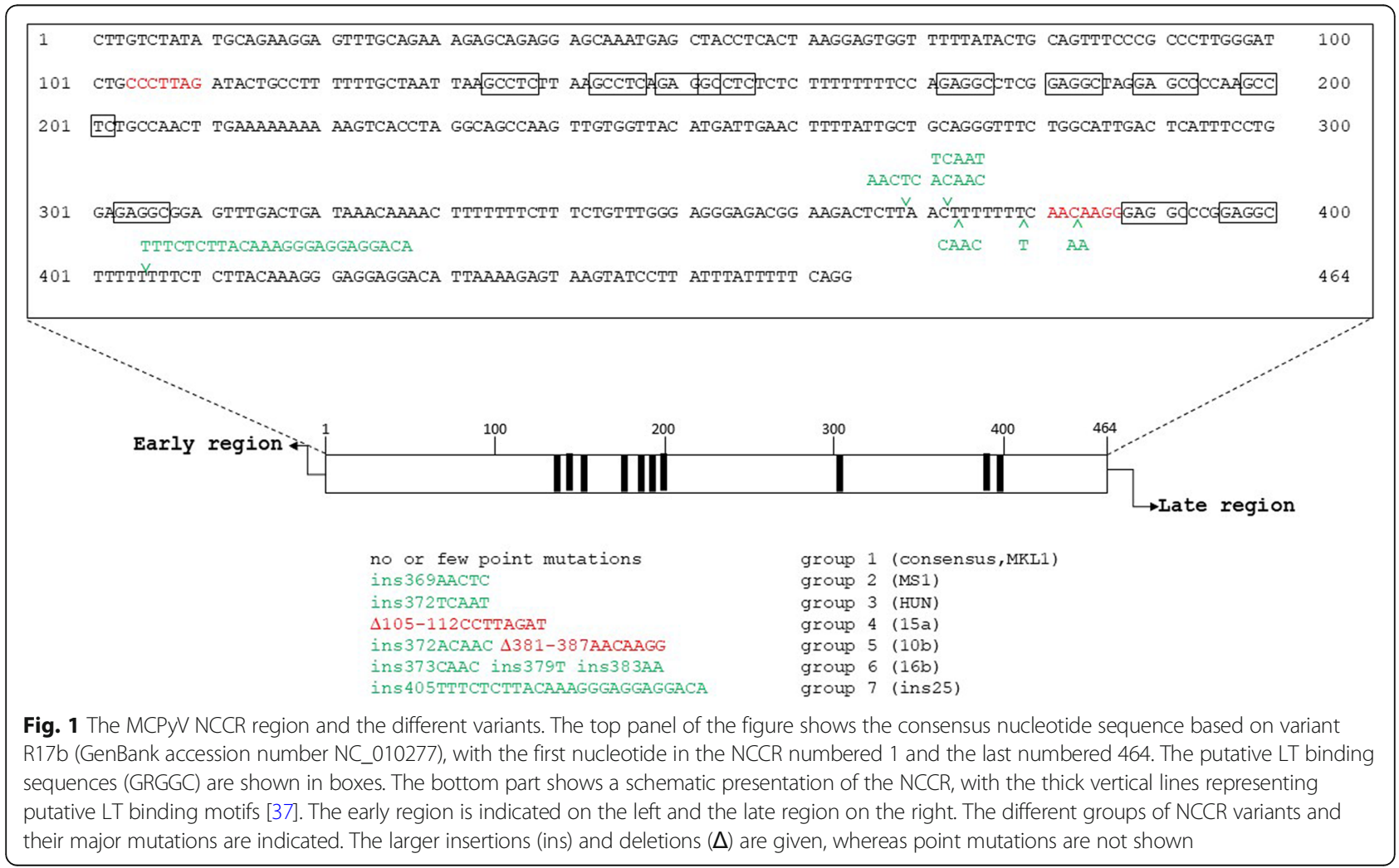


Table 1 MCPyV NCCR variants examined in this study

\begin{tabular}{lllll}
\hline Group & NCCR variant & Referred to in this paper & Source & Reference \\
\hline 1 & R17b & cons-E and cons-L & healthy skin & [20] \\
& MKL-1 & MKL1-E and MKL1-L & MCC & [38] \\
2 & MS-1 & MS1-E and MS1-L & MCC & [1] \\
3 & $7673 / 2011 / H U N$ & HUN-E and HUN-L & metastatic cervical lymph node & {$[39]$} \\
4 & R15a & 15a-E and 15a-L & healthy skin & [20] \\
5 & R10b & 10b-E and 10b-L & healthy skin & [20] \\
7 & R16b & 16b-E and 16b-L & healthy skin & [20] \\
\hline
\end{tabular}

sewage water (see Table 1 for references). The mutations for each NCCR variant are presented in Supplementary Table S3.

\section{Basal early and late promoter activities in MCC13 and human dermal fibroblasts cells}

Because MCPyV-positive Merkel cell carcinoma derives from virus-transformed Merkel cells [1], and human dermal fibroblasts (HDF) have been shown to be permissive for this virus and considered as genuine host cells for the virus [19], we examined the basal early and late promoter activity of MCPyV variants in these two cell lines. To study the effect of mutations in the NCCR on basal early and late promoter activity, one NCCR variant was selected from each group, with the exception of group 1, in which both the consensus sequence and a variant with few point mutations were tested (Table 1). The NCCRs were cloned in both orientations, and the basal early and late promoter activities were monitored in the MCPyVnegative $\mathrm{MCC}$ cell line $\mathrm{MCC} 13$, in addition to primary dermal fibroblasts.

Comparing the relative basal early and late promoter activities showed that both promoters were stronger in HDF cells compared to MCC13 cells (Supplementary Fig. S1). The cons-E promoter was $\sim 4$-fold stronger, while the cons- $\mathrm{L}$ was $\sim 3 \mathrm{x}$ stronger. The difference is probably even more because the transfection efficiency in MCC13 cells was approximately $60-70 \%$, whereas in HDF the transfection efficiency was estimated to be $30 \%$ (results not shown). Comparing the cons-E and cons-L in MCC13 revealed that the late promoter was approximately $8 \mathrm{x}$ stronger than the early promoter. The cons-L was approximately $6 \mathrm{x}$ stronger in HDF than in MCC13 cells (Supplementary Fig. S1).

\section{Effect of large T-antigen on early and late promoter activities}

Large $\mathrm{T}$-antigen of polyomaviruses has been shown to affect the early and late promoter activities. To examine the effect of LT on the MCPyV promoters, we cotransfected MCC13 cells with $1 \mu \mathrm{g}$ luciferase reporter plasmid with the cons-E promoter, with increasing amounts (0, 100, 200,400, 500, 800 and $1000 \mathrm{ng}$ ) of empty pcDNA3.1 vector or LT expression vector. All concentrations reduced cons-E promoter activity (results not shown), but high concentrations (800 and $1000 \mathrm{ng}$ ) of empty vector almost completely inhibited MCPyV promoter activity. Both the empty vector and the LT expression plasmid contain the strong CMV immediate early promoter. We found this promoter to be $>5$-fold stronger than the cons-E promoter in MCC13 cells and 40x stronger in HDF cells (Supplementary Fig. S2). We decided to test the effect of two different concentrations (100 and $500 \mathrm{ng}$ ) of LT expression plasmid on all variant NCCRs. Both concentrations of LT expression plasmid (100 ng and $500 \mathrm{ng}$ ) significantly reduced the activity of all early promoters in MCC13 cells (Fig. 3a and b). A similar effect was observed for the late promoters, with the exception of the MS1 and HUN promoters, which were induced when cells were co-transfected with 500 ng of LT expression plasmid (Fig. 3c and d).

We also examined the effect of LT on the MCPyV promoters in HDF cells. Both concentrations of LT expression plasmid (100 ng and $500 \mathrm{ng}$ ) significantly repressed the early promoter activity (Fig. 4a and b) and the late promoter activity (Fig. 4c and d) of all variant NCCRs tested. However, a somewhat stronger inhibition was observed with the lowest concentration of LT expression plasmid, while at higher concentrations promoter interference becomes more pronounced.

MCPyV-positive MCCs contain integrated viral DNA, and are further characterized by the expression of a Cterminal truncated LT [Feng, 2008]. Thus, we examined the effect of truncated LT on the early and late promoter. Of the seven different strains examined in this work, only MKL-1 and MS-1 have been isolated from MCC [40, 41], whereas the HUN strain was obtained from a metastatic cervical lymph node from a Hungarian patient, though no further information is available [39]. We therefore decided to test the impact of MKL-1 (MS1 , respectively) truncated LT on their cognate promoter. The luciferase reporter plasmids with the early or late 

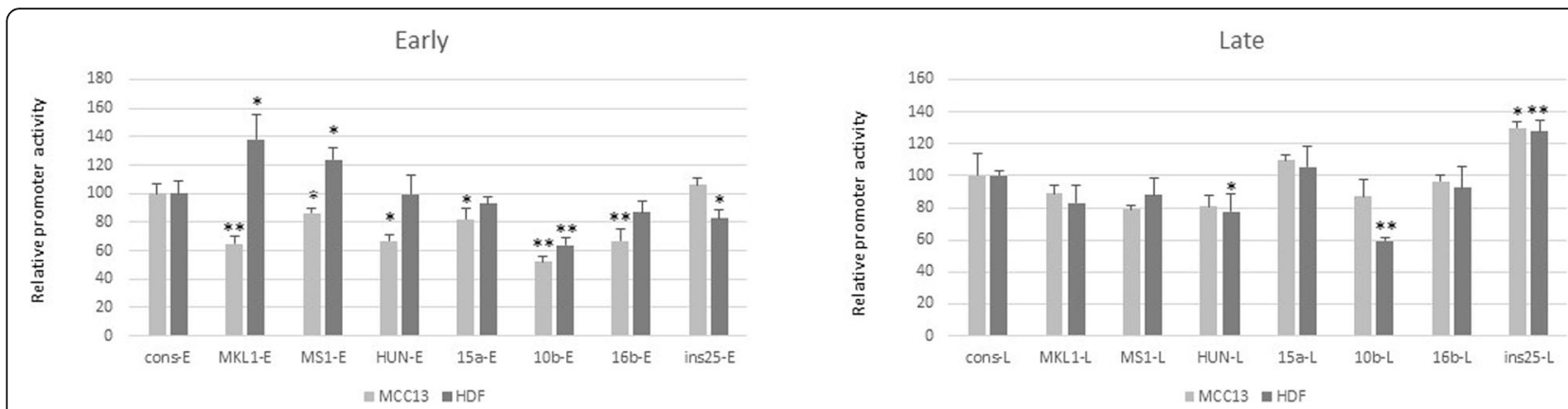

Fig. 2 Relative promoter activities of different MCPyV NCCR variants in MCC13 and human dermal fibroblast cells. Cells in 12-well plates were transiently transfected with $1 \mathrm{\mu g}$ luciferase reporter plasmid containing the early promoter of MCPyV. Luciferase activity was corrected for total protein concentration of the sample, and the corrected value for the early consensus (late consensus, respectively) promoter was arbitrarily set as $100 \%$. Each bar represents the average of three independent parallels + standard deviation. A representative result is shown, and each promoter was tested at least three times in independent experiments with similar results; ${ }^{*} p<0.05,{ }^{* *} p<0.01$

promoter of MKL-1 (MS-1, respectively) were cotransfected with an expression plasmid for MKL-1 LT (MS-1 LT, respectively) in MCC13 and in HDF cells, and the promoter activity was monitored. Truncated MKL-1 LT stimulated the MKL-1 early and late promoter activities in both MCC13 and HDF cells (Fig. 5a and b). The only exception was when $500 \mathrm{ng}$ of MKL-1
LT expression plasmid was used, with a significant inhibition of the early promoter observed in HDF cells (Fig. 5b). Truncated MS-1 LT also stimulated the early and late MS-1 promoter in MCC13 cells and the late promoter in HDF cells (Fig. 5a and b), but inhibited the early promoter in HDF cells (Fig. 5b). With $100 \mathrm{ng}$ of truncated MS-1 LT expression plasmid, a reduction in

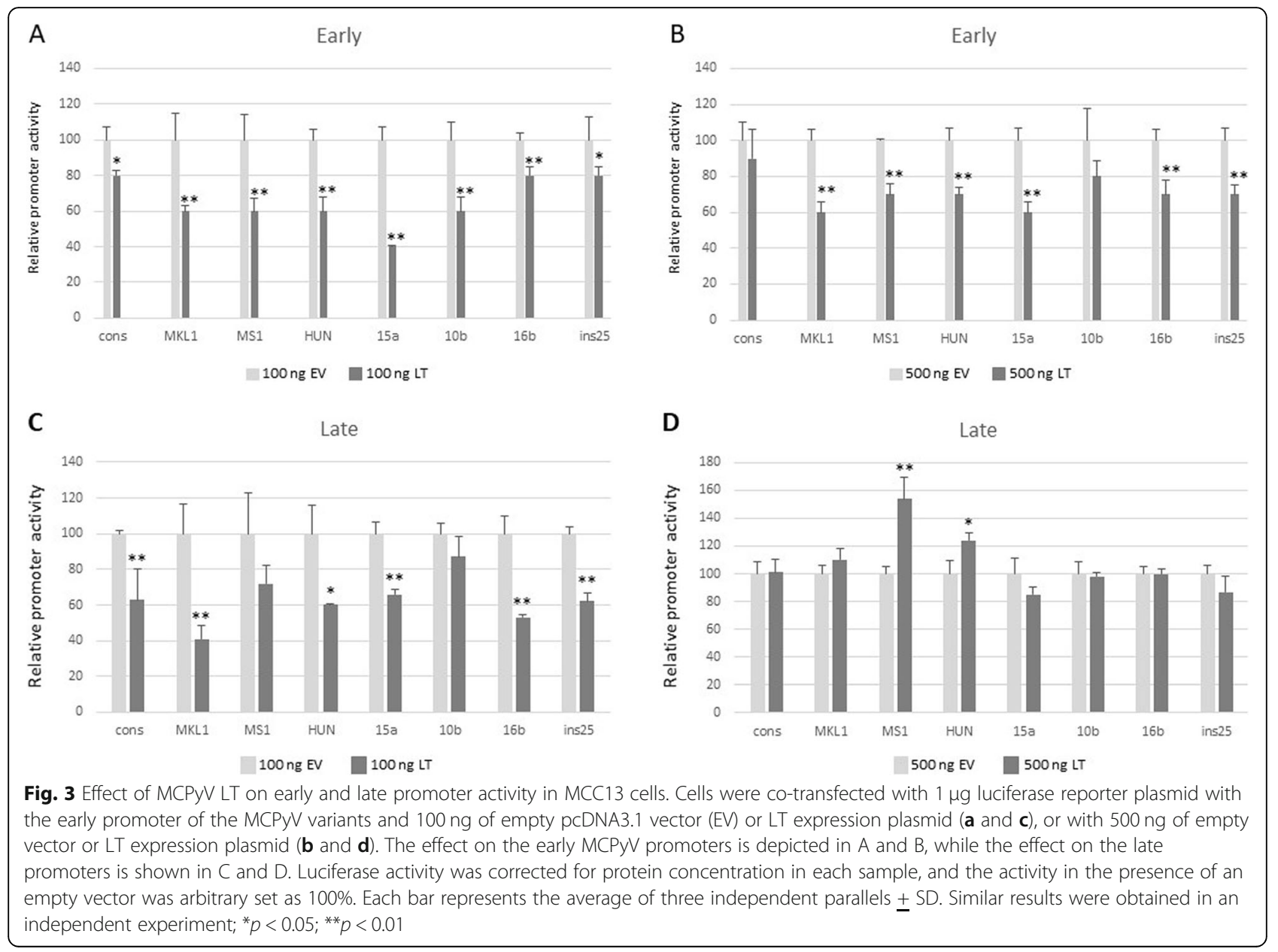




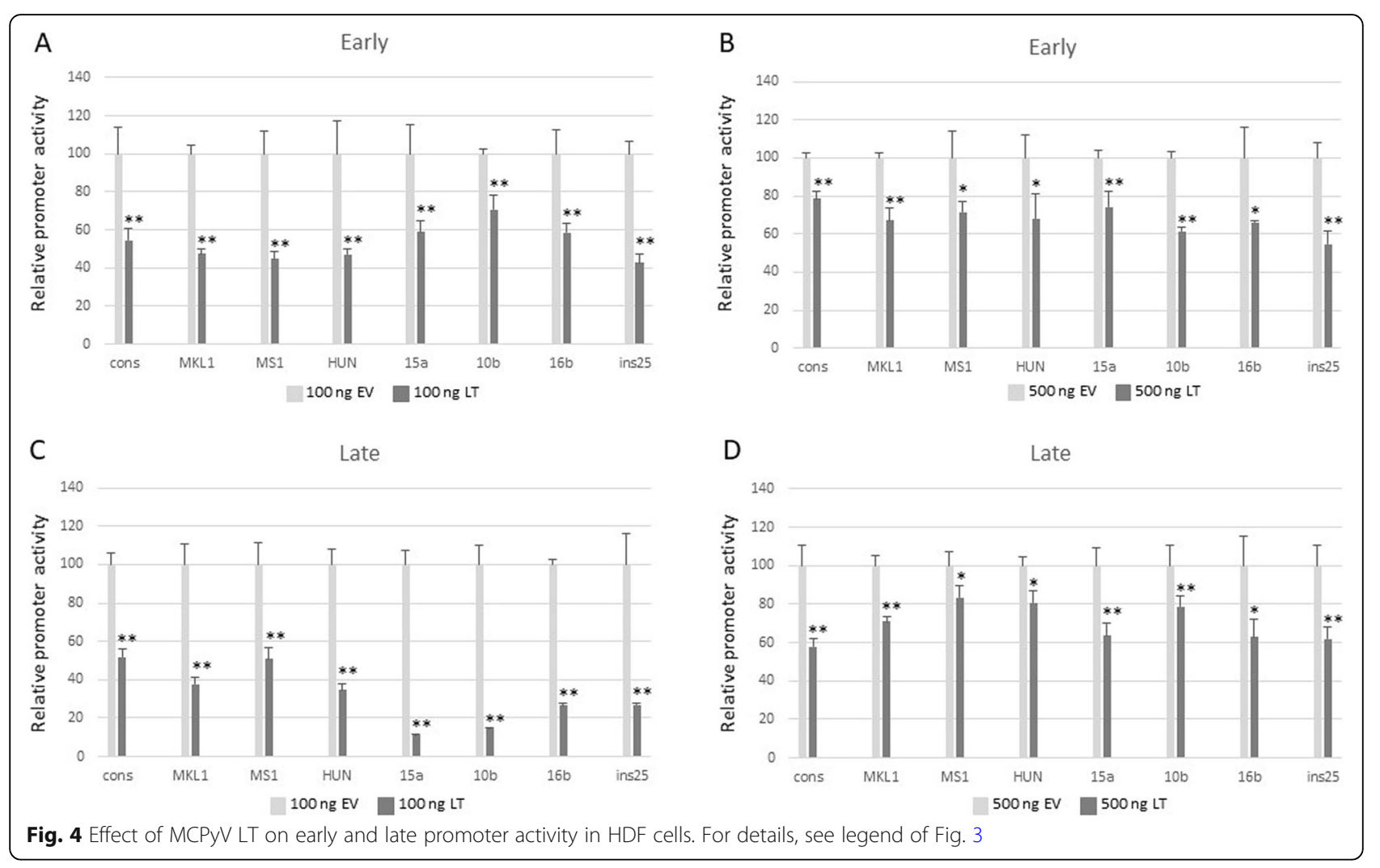

promoter activity of $15-24 \%$ compared to the control was observed. However, this decrease was not significant ( $p$-values between 0.0553 and 0.0632 in the different experiments).

\section{Discussion}

MCPyV has a seroprevalence of approximately $80 \%$ in the healthy, adult population [13-18]. MCPyV is chronically shed from healthy skin [20], but can also cause an aggressive skin cancer known as Merkel cell carcinoma [1]. Several MCPyV variants have been described with mutations in their NCCR (Supplementary Table S3). These variants have been isolated from both healthy tissue and tumors, but so far, no typical strain seems to be associated with MCC (Supplementary Table S3). The mutations described in the known MCPyV variants could be classified in seven groups with group 1 containing the most common NCCR, which was referred to as the consensus sequence in our study and variants with one or a few point mutations. Groups 2-7 contain insertions and/or deletions in their NCCR. Significant differences in basal early and late promoter activities in HDF and MCC13 cells were observed. The basal early-, as well as late promoter activity, of all variants tested was higher in HDF cells than in MCC13 cells despite a lower transfection efficiency (Fig. 6). This may indicate that the $\mathrm{MCPyV}$ promoter is more adapted to the former cell type. HDF have been suggested as natural host cells for the virus and are permissive for the virus, while the infection of Merkel cells and the subsequent transformation of these cells could be seen as an accidental and unfortunate event [19].

Co-transfection with a $100 \mathrm{ng}$ of full-length LT expression plasmid resulted in reduced early and late promoter activity of all variants in both MCC13 and HDF cells (Fig. 6). However, $500 \mathrm{ng}$ of LT expression plasmid reduced early and late promoter activities in HDF and early promoter activity in MCC13 cells, but had only a slight or no effect, but significantly stimulated the HUN and MS1 (a 20 and 40\% increase, respectively) late promoters. Kwun et al. found that MCPyV LT repressed early and late promoter activity of $\mathrm{MCPyV}$ isolate MCC339 in HEK293 cells, but they did not examine the effect of LT in MCC13 or HDF cells [42]. Yet, in another study by Ajuh and co-workers, the authors showed that LT trans-activated the MCPyV R17b (= consensus) early and late promoter in HEK293T cells [29]. The discrepancy between their results and the findings by Kwun et al. and us can be explained by the use of different LT. HEK293T cells express both SV40 LT and sT, but not MCPyV LT [29]. Moreover, the possible contribution of $\mathrm{sT}$ in the trans-activation of the early and late MCPyV promoters in these cells was not investigated. Furthermore, Ajuh et al. studied the 


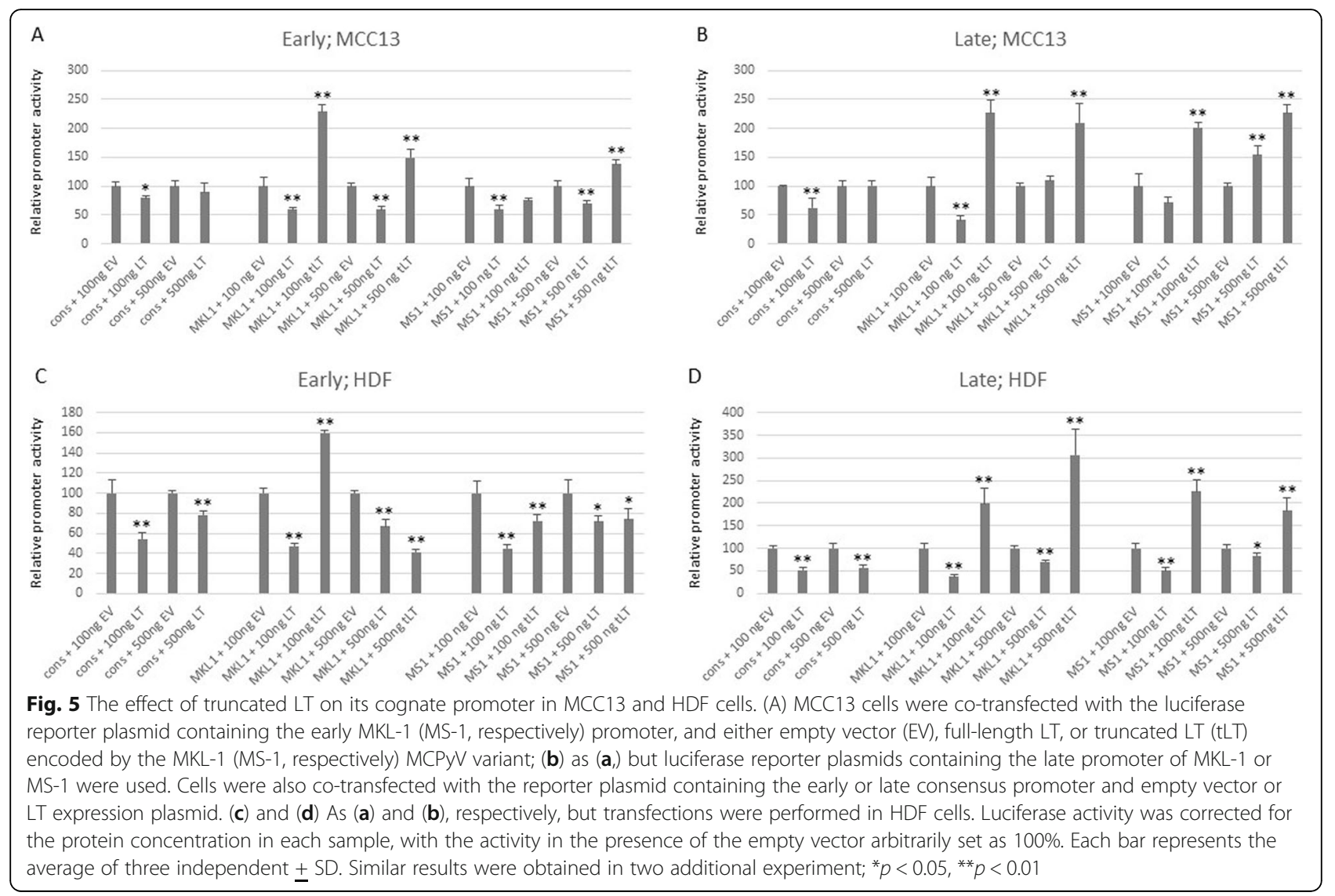

effect of LT using a bidirectional reporter vector, thereby allowing for the simultaneous monitoring of the early and late promoter activity, whereas both we and Kwun et al. examined early and late promoter independently, which better reflects the situation in infected cells. Indeed, during the polyomavirus life cycle, early and late promoters are activated in a time-dependent fashion. The early promoter is active early during infection, and the expression of LT will result in the autorepression of the early promoter and a switch to activation of the late promoter [43]. Another experimental difference was that we measured promoter activities $24 \mathrm{~h}$ after transfection, whereas Ajuh and colleagues determined promoter activities $48 \mathrm{~h}$ post transfection. Lastly, we used dose-dependent studies with LT, while Ajuh and co-workers used cells constitutively expressing LT. The authors also examined the effect of MCPyV LT on early and late promoter activity of the consensus MCPyV variant and MCVw156 (consensus with one substitution and one deletion; Supplementary Table S3) in HEK293MCT cells (i.e. HEK293 cells stably expressing MCPyV LT). While early promoters of both MCPyV variants were significantly stimulated by MCPyV LT, no effect was observed on their late promoter. A possible explanation for the different effects of SV40 LT and MCPyV LT on the MCPyV late promoter was not provided by the authors.

Because the viral genome in MCC expresses a truncated LT, we examined the effect of truncated LT on its cognate promoter. Truncated MKL-1 (MS-1, respectively) LT stimulated its cognate early and late promoter in MCC13 cells, whereas stimulation was only observed for the late promoter in HDF cells. In these cells, truncated MKL-1 and MS-1 LT inhibited the corresponding early promoter. The reason for the cell-specific effect of truncated LT on the MCPyV promoter is not known, but MCPyV LT has been shown to interact with several cellular factors [42]. Different interaction partners in distinct cell types may determine the effect of LT on the MCPyV promoter activity. The fact that truncated LT stimulates their cognate early promoter in MCC13 may indicate a positive feedback loop that results in higher expression levels of the early proteins, including the oncoproteins ST and LT. Our preliminary results shows that also truncated MKL-2 LT (which differs from HUN truncated LT by replacement of Ala20 into Ser and Ser263 into Phe, and the lack of the three C-terminal amino acids Ser-Arg-Lys) was able to stimulate the HUN-E promoter approximately 2 -fold in MCC13 cells (our unpublished results), suggesting that it may be a 


\begin{tabular}{|c|c|c|c|c|c|c|}
\hline & MCC13 & HDF & $\begin{array}{c}\text { MCC13 } \\
+ \text { +100ng LT }\end{array}$ & $\begin{array}{c}\text { MCC13 } \\
+500 \text { ng LT }\end{array}$ & $\begin{array}{c}\text { HDF } \\
+100 \text { ng LT }\end{array}$ & $\begin{array}{c}\text { HDF } \\
+500 \text { ng LT }\end{array}$ \\
\hline cons-E & 100 & 100 & 80 & 90 & 53,4 & 78,5 \\
\hline cons-L & 100 & 100 & 63 & 101 & 51,8 & 57,7 \\
\hline MKL1-E & 65 & 138,2 & 60 & 60 & 47,5 & 66,9 \\
\hline MKL1-L & 89 & 82,9 & 41 & 110 & 37,6 & 70,9 \\
\hline MS1-E & 86 & 124 & 60 & 70 & 44,6 & 71,5 \\
\hline MS1-L & 78,8 & 88 & 72 & 154 & 50,8 & 83,5 \\
\hline HUN-E & 67 & 99,6 & 60 & 70 & 46,9 & 67,9 \\
\hline HUN-L & 80,8 & 78,5 & 60 & 124 & 34,5 & 80,8 \\
\hline 15a-E & 82 & 92,9 & 40 & 60 & 58,9 & 74 \\
\hline $15 a-L$ & 109,4 & 105,6 & 66 & 85 & 11 & 63,5 \\
\hline 10b-E & 52 & 64 & 60 & 80 & 70,7 & 61,2 \\
\hline $10 \mathrm{~b}-\mathrm{L}$ & 86,8 & 59,5 & 87 & 98 & 14,4 & 78,7 \\
\hline $16 \mathrm{~b}-\mathrm{E}$ & 67 & 86,7 & 80 & 70 & 58,5 & 66 \\
\hline $16 \mathrm{~b}-\mathrm{L}$ & 96,6 & 92,3 & 53 & 100 & 26,4 & 63 \\
\hline ins25-E & 106 & 82,5 & 80 & 70 & 42,8 & 54,5 \\
\hline ins25-L & 130 & 127,5 & 62 & 87 & 26,8 & 62 \\
\hline & & & & & & \\
\hline \multicolumn{7}{|c|}{$\begin{array}{l}\mathbf{0} \\
\text { Fig. } \mathbf{6} \text { Heatmap showing the relative promoter activities of eight MCPyV NCCR variants in MCC13 and human dermal fibroblasts (HDF) in the } \\
\text { absence and presence of large T antigen (LT). The activity of the consensus NCCR (Cons) was arbitrary set as } 100 \text { and the activities of the other } \\
\text { promoters were related to this }\end{array}$} \\
\hline
\end{tabular}

common feature of truncated LT to autostimulate its expression. This positive autoregulation of LT and sT could be potentially important for tumorigenesis. Since fulllength LT had an inhibitory effect on the promoters, it would be interested to test whether full-length LT reverses the activity of truncated LT. However, to be of biological relevance, both full-length and truncated LT must be coexpressed in MCPyV infected cells. To our best knowledge, only truncated LT is expressed in virus-positive MCCs. We are aware of only two studies were coexpression of full-length and truncated LT was observed. One case of non small cell lung cancer (a squamous cell carcinoma) with both episomal and integrated viral DNA and both full-length and truncated LT protein was described by Hashida and co-workers [44]. In another study, mRNAs for truncated and full- length LT were confirmed by highly sensitive qRT-PCR in two cases of chronic lymphocytic leukemia, but expression of truncated and full-length LT at protein level was not investigated [45]. The genome copy per chronic lymphocytic leukemia cell was 3 to 4 logs lower than MCPyV-positive MCCs, suggesting that very low levels of LT/truncated LT are present in these cells. It remains to be determined whether such low levels have any biological relevance for the viral life cycle or tumorigenesis. Because integration of the
$\mathrm{MCPyV}$ genome interrupts the late region, no late proteins are expressed and no viral particles are produced. The biological implication of enhanced late promoter activity by truncated LT in MCC remains elusive.

Our transient transfection studies showed that the MCPyV NCCR variants possess different promoter activity, and can lead to different expression levels of the viral proteins. This has been confirmed by in situ studies. The CVG-1 and MKL-1 MCC cell lines both contain seven copies of the integrated virus genome per diploid cell [46]. The CVG-1 cell line contains the consensus NCCR sequence, while MKL-1 contains one single point mutation (T52C; Supplementary Table S2). Quantitative real-time PCR demonstrated that the total LT and sT mRNA expression levels were approximately 2.5 times higher in CVG-1 cells compared to MKL-1 cells, thus indicating that the former promoter is $2.5 \mathrm{x}$ stronger than the latter. Our transient transfection study in MCC13 cells confirmed that the MKL-1 early promoter was weaker than the consensus early promoter (Fig. 2). The expression levels of early proteins in MCC not only depend on the strength of the early promoter, but the number of integrated viral genomes and the integration site (hetero- versus euchromatin) may also influence the promoter strength. Velásquez et al. determined that MKL-2 and 
MS-1 MCC cells contain two and four genome copies per diploid cells, respectively [46]. The LT transcript levels were approximately 2-fold higher in MS-1 cells compared to the MKL-2 cells, while the ST mRNA levels were $4 \mathrm{x}$ higher in MS-1 cells than in MKL-2 cells. The complete NCCR sequence of the MKL-2 variant has not been determined, but the 240 nucleotides downstream of the LT start codon are identical with the consensus sequence.

The MCPyV NCCR contains a plethora of putative transcription factor binding motifs (see Supplementary Fig. 3 and Supplementary Table S4), but the binding of the corresponding transcription factor has not been confirmed. Whether the mutations found in these sites in the NCCR variants we investigated abolished binding of the transcription factor, has not been tested. The $25 \mathrm{bp}$ insertion generates putative binding motifs for the transcription factors FOXO3a, SRY, Elk-1 and p300, but their possible role in regulating the promoter activity remains to be investigated.

\section{Conclusions}

Our study shows that the promoters of different MCPyV isolates possess unlike transcriptional activity, and that fulllength LT and MCC-associated truncated LT have a distinct impact on the promoter. Whether these differences in promoter activity contribute to the replication and transformation properties of the virus remains to be determined.

\section{Supplementary information}

Supplementary information accompanies this paper at https://doi.org/10. 1186/s12985-020-01317-x.

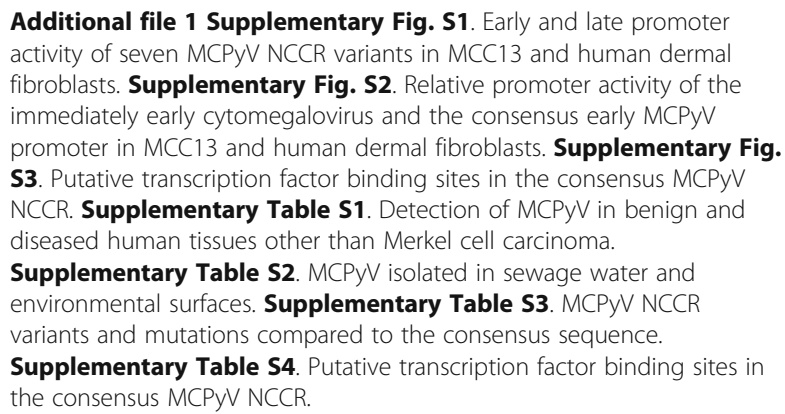

\section{Abbreviations}

HDF: Human dermal fibroblasts; LT: Large T antigen; MCC: Merkel cell carcinoma; MCPyV: Merkel cell polyomavirus; NCCR: Non-coding control region; sT: Small T antigen; tLT: Truncated large T antigen

\section{Acknowledgments}

The authors wish to thank Dr. Baki Akgül from the University of Cologne, Germany for providing MCC13 cells.

\section{Authors' contributions}

Conceptualization, U.M. and B.E.; experiments, I.A., K.R., and U.M.; validation, B.E., U.M.; writing —original draft preparation, U.M. and B.E.; writing-review and editing, I.A., K. R, B.S., E. B, and U.M.; supervision, U.M. and B.S.; project administration, U.M.; funding acquisition, U.M. and B.S. The author (s) read and approved the final manuscript.

\section{Funding}

This research was funded by "Helse-Nord Forskningsmidler" project 23226. The APC was funded by the UiT, The Arctic University of Norway.

\section{Availability of data and materials}

The datasets used and/or analysed during the current study are available from the corresponding author on reasonable request.

Ethics approval and consent to participate

Not applicable.

\section{Consent for publication}

Not applicable.

\section{Competing interests}

The authors declare that they have no competing interests.

\section{Author details}

'Molecular Inflammation Research Group, Department of Medical Biology, Faculty of Health Sciences, University of Tromsø, The Arctic University of Norway, Troms $\varnothing$, Norway. ${ }^{2}$ Present address: Tumor Biology Research Group, Department of Medical Biology, Faculty of Health Sciences, University of Troms $\varnothing$, The Arctic University of Norway, Tromsø, Norway. ${ }^{3}$ Division 12 Measles, Mumps, Rubella and Viruses Affecting Immunocompromised

Patients, Robert Koch Institute, Berlin, Germany.

Received: 19 December 2019 Accepted: 10 March 2020 Published online: 19 April 2020

\section{References}

1. Feng $H$, Shuda $M$, Chang $Y$, Moore PS. Clonal integration of a polyomavirus in human Merkel cell carcinoma. Science. 2008;319:1096-100. https://doi. org/10.1126/science.1152586.

2. Kassem A, Schöpflin A, Diaz C, Weyers W, Stickler E, Werner M, Zur HA Frequent detection of Merkel cell polyomavirus in human Merkel cell carcinomas and identification of a unique deletion in the VP1 gene. Cancer Res. 2008:68:5009-13. https://doi.org/10.1158/0008-5472.CAN-08-0949.

3. Foulongne V, Kluger N, Dereure O, Brieu N, Guillot B, Segondy M. Merkel cell polyomavirus and Merkel cell carcinoma. France Emerg Dis. 2008;14: 1491-3. https://doi.org/10.3201/eid1409.080651.

4. Becker JC, Houben R, Ugurel S, Trefzer U, Pföhler C, Schrama D. MC polyomavirus is frequently present in Merkel cell carcinoma of European patients. J Invest Dermatol. 2009;129:248-50. https://doi.org/10.1038/jid.2008.198.

5. Van Ghelue M, Moens U. Merkel cell polyomaviurs: a causal factor in Merkel cell carcinoma. In: La Porta CAM, editor. Skin cancers-risk factors, prevention and therapy. Croatiia: IntechOpen; 2011. p. 109-42. https://doi.org/10.5772/25675.

6. Wendzicki JA, Moore PS, Chang Y. Large T and small T antigens of Merkel cell polyomavirus. Curr Opin Virol. 2015;11:38-43. https://doi.org/10.1016/j. coviro.2015.01.009

7. Shuda M, Guastafierro A, Geng X, Shuda Y, Ostrowski SM, Lukianov S, Jenkins FJ, Honda K, Maricich SM, Moore PS, Chang Y. Merkel cell Polyomavirus small T antigen induces Cancer and embryonic Merkel cell proliferation in a transgenic mouse model. PLoS One. e01423292015;10. https://doi.org/10.1371/journal.pone.0142329.

8. Verhaegen ME, Mangelberger D, Harms PW, Vozheiko TD, Weick JW, Wilbert DM, Saunders TL, Ermilov AN, Bichakjian CK, Johnson TM, Imperiale MJ, Dlugosz AA. Merkel cell polyomavirus small T antigen is oncogenic in transgenic mice. J Invest Dermatol. 2015;135:1415-24. https://doi.org/10.1038/jid.2014.446.

9. Spurgeon ME, Cheng J, Bronson RT, Lambert PF, DeCaprio, J.A. Tumorigenic activity of merkel cell polyomavirus T antigens expressed in the stratified epithelium of mice. Cancer Res 2015;75:1068-1079. doi: https://doi.org/10. 1158/0008-5472.CAN-14-2425.

10. Bouvard V, Baan RA, Grosse Y, Lauby-Secretan B, El Ghissassi F, BenbrahimTallaa L, Guha N, Straif K. Carcinogenicity of malaria and of some polyomaviruses. Lancet Oncol. 2012;13:339-40.

11. Stakaityte G, Wood JJ, Knight LM, Abdul-Sada H, Adzahar NS, Nwogu N, Macdonald A, Whitehouse A. Merkel cell polyomavirus: molecular insights into the most recently discovered human tumour virus. Cancers. 2014;6: 1267-97. https://doi.org/10.3390/cancers6031267.

12. Borchert S, Gech-Sioli M, Neumann F, Schmidt C, Wimmer P, Dobner T, Grundhoff A, Fischer N. High-affinity Rb binding, p53 inhibition, subcellular 
localization, and transformation by wild-type or tumor-derived shortened Merkel cell polyomavirus large T antigens. J Virol. 2014;88:3144-60. https:// doi.org/10.1128/JVI.02916-13.

13. Viscidi RP, Rollison DE, Sondak VK, Silver B, Messina JL, Giuliano AR, Fulp W, Ajidahun A, Rivanera D. Age-specific seroprevalence of Merkel cell polyomavirus, BK virus, and JC virus. Clin Vaccine Immunol. 2011;18:1737-43. https://doi.org/10.1128/CVI.05175-11.

14. Kean JM, Rao S, Wang M, Garcea RL. Seroepidemiology of human polyomaviruses. PLoS Pathog. 2009;5:e1000363. https://doi.org/10.1371/ journal.ppat.1000363.

15. Zhang C, Liu F, He Z, Deng Q, Pan Y, Liu Y, Zhang C, Ning T, Guo C, Liang $Y$, Xu R, Zhang L, Cai H, Ke Y. Seroprevalence of Merkel cell polyomavirus in the general rural population of Anyang. China PLoS One. 2014;9:e106430. https://doi.org/10.1371/journal.pone.0106430.

16. Martel-Jantin C, Pedergnana V, Nicol JT, Leblond V, Tregouet DA, Tortevoye P, Plancoulaine S, Coursaget P, Touze A, Abel L. Gessain, A. Merkel cell polyomavirus infection occurs during early childhood and is transmitted between siblings. J Clin Virol 2013;58:288-291. doi: https://doi.org/10.1016/j.jcv.2013.06.004.

17. Nicol J, Robinot R, Carpentier A, Carandina G, Mazzoni E, Tognon M, Touze A, Coursaget P. Age-specific seroprevalences of merkel cell polyomavirus, human polyomaviruses 6, 7, and 9, and trichodysplasia spinulosa-associated polyomavirus. Clin Vaccine Immunol. 2013;20:363-8. https://doi.org/10.1128/CVI.00438-12.

18. Kamminga S. E van der Meijden E, Feltkamp MCW. Zaaijer HL Seroprevalence of fourteen human polyomaviruses determined in blood donors PLoS One. 2018;13:e0206273. https://doi.org/10.1371/journal.pone.0206273.

19. Liu W, Yang R, Payne AS, Schowalter RM, Spurgeon ME, Lambert PF, Xu X, Buck CB, You J. Identifying the target cells and mechanisms of Merkel cell Polyomavirus infection. Cell Host Microbe. 2016;19:775-87. https://doi.org/ 10.1016/j.chom.2016.04.024

20. RM RS, Pastrana DV, Pumphrey KA, Moyer AL, Buck CB. Merkel cell polyomavirus and two previously unknown polyomaviruses are chronically shed from human skin. Cell Host Microbe. 2010;7:509-15. https://doi.org/10. 1016/j.chom.2010.05.006

21. Foulongne V, Sauvage V, Hebert C, Dereure O, Cheval J, Gouilh MA, Pariente K, Segondy M, Burguiere A, Manuguerra JC, Caro V, Eloit M. Human skin microbiota: high diversity of DNA viruses identified on the human skin by high throughput sequencing. PLoS One. 2012;7:e38499. https://doi.org/10. 1371/journal.pone.0038499.

22. Hashida Y, Kamioka M, Tanaka M, Hosokawa S, Murakami M, Nakajima K, Kikuchi H, Fujieda M, Sano S, Daibata M. Ecology of Merkel cell Polyomavirus in healthy skin among individuals in an Asian cohort. J Infect Dis. 2016;213:1708-16. https://doi.org/10.1093/infdis/jiw040.

23. Csoboz B, Rasheed K, Sveinbjørnsson U. Moens U. Merkel cell polyomavirus and non-Merkel cell carcinomas: guilty or circumstantial evidence? APMIS. 2020; [Online ahead of print]. https://doi.org/10.1111/apm.13019.

24. Moens U, Van Ghelue M, Ludvigsen M, Korup-Schulz S, Ehlers B. The early and late promoters of BKPyV, MCPyV, TSPyV, and HPyV12 are among the strongest of all known human polyomaviruses in 10 different cell lines. J Gen Virol. 2015;96:2293-303. https://doi.org/10.1099/vir.0.000181.

25. Moens U, Song X, Van Ghelue M, Lednicky JA, Ehlers, B. A Role of Sp1 Binding Motifs in Basal and Large T-Antigen-Induced Promoter Activities of Human Polyomavirus HPyV9 and Its Variant UF-1. Int J Mol Sci. 2017;18:pii: E2414. doi: https://doi.org/10.3390/ijms18112414.

26. Song X, Van Ghelue M, Ludvigsen M, Nordbo SA, Ehlers B, Moens U. Characterization of the non-coding control region of polyomavirus $\mathrm{KI}$ isolated from nasopharyngeal samples from patients with respiratory symptoms or infection and from blood from healthy blood donors in Norway. J Gen Virol. 2016;97:1647-57. https://doi.org/10.1099/jgv.0.000473.

27. Gosert R, Rinaldo CH, Funk GA, Egli A, Ramos E, Drachenberg CB, Hirsch HH. Polyomavirus $\mathrm{BK}$ with rearranged noncoding control region emerge in vivo in renal transplant patients and increase viral replication and cytopathology. J Exp Med. 2008;205:841-52. https://doi.org/10.1084/jem.20072097.

28. Gosert R, Kardas P, Major EO, Hirsch HH. Rearranged JC virus noncoding control regions found in progressive multifocal leukoencephalopathy patient samples increase virus early gene expression and replication rate. J Virol. 2010;84:10448-56. https://doi.org/10.1128/JVI.00614-10.

29. Ajuh ET, Wu Z, Kraus E, Weissbach FH, Bethge T, Gosert R, Fisher N, Hirsch $\mathrm{HH}$. Novel human polyomavirus noncoding control region differ in bidirectional gene expression according to host cell, large T-antigen expression, and clinically occurring rearrangements. J Virol. 2018;92:e0223117. https://doi.org/10.1128/JVI.02231-17.
30. Barcena-Panero A, Echevarria JE, Van Ghelue M, Fedele G, Royuela E, Gerits $\mathrm{N}$, Moens U. BK polyomavirus with archetypal and rearranged non-coding control regions is present in cerebrospinal fluids from patients with neurological complications. J Gen Virol. 2012;93:1780-94. https://doi.org/10. 1099/vir.0.042143-0.

31. Van Loy T, Thys K, Ryschkewitsch C, Lagatie O, Monaco MC, Major EO, Tritsmans L, Stuyver LJ. JC virus quasispecies analysis reveals a complex viral population underlying progressive multifocal leukoencephalopathy and supports viral dissemination via the hematogenous route. J Virol. 2015;89: 1340-7. https://doi.org/10.1128/JVI.02565-14.

32. L'Honneur AS, Leh H, Laurent-Tchenio F, Hazan U, Rozenberg F, Bury-Mone $\mathrm{S}$. Exploring the role of NCCR variation on JC polyomavirus expression from dual reporter minicircles. PLoS One. 2018;13:e0199171. https://doi.org/10. 1371/journal.pone.0199171.

33. Takahashi K, Sekizuka T, Fukumoto H, Nakamichi K, Suzuki T, Sato $Y$, Hasegawa H, Kuroda M, Katano H. Deep-Sequence Identification and Role in Virus Replication of a JC Virus Quasispecies in Patients with Progressive Multifocal Leukoencephalopathy. J Virol. 2016;91:pii: e01335-e01316. doi: https://doi.org/10.1128/JVI.01335-16.

34. Hashida Y, Higuchi T, Matsui K, Shibata Y, Nakajima K, Sano S, Daibata M. Genetic variability of the noncoding control region of cutaneous Merkel cell Polyomavirus: identification of geographically related genotypes. J Infect Dis. 2018;217:1601-11. https://doi.org/10.1093/infdis/jiy070.

35. Rasheed K, Abdulsalam I, Fismen S, Grimstad $\varnothing$, Sveinbjornsson B, Moens U. CCL17/TARC and CCR4 expression in Merkel cell carcinoma. Oncotarget. 2018:9:31432-47. https://doi.org/10.18632/oncotarget.25836.

36. Pannuti A, Pascucci A, La Mantia G, Fisher-Fantuzzi L, Vesco C, Lania L. Trans-activation of cellular and viral promoters by a transforming nonkaryophilic simian virus 40 large T antigen. J Virol. 1987;61:1296-9.

37. Harrison C, Jiang T, Banerjee P, Meinke G, D'Abramo CM, Schaffhausen B, Bohm A. Polyomavirus large $T$ antigen binds symmetrical repeats at the viral origin in an asymmetrical manner. J Virol. 2013;87:13751-9. https://doi. org/10.1128/JVI.01740-13.

38. Shuda M, Feng H, Kwun HJ, Rosen ST, Gjoerup O, Moore PS, Chang Y. T antigen mutations are a human tumor-specific signature for Merkel cell polyomavirus. Proc Natl Acad Sci U S A. 2008;105:16272-7. https://doi.org/ 10.1073/pnas.0806526105.

39. Horvath KB, Pankovics P, Battyani Z, Kalman E, Reuter G. A probable etiological role of Merkel cell polyomavirus in the development of Merkel cell carcinoma. Orv Hetil. 2013;154:102-12. https:/doi.org/10.1556/OH.2013.29525.

40. Rosen ST, Gould VE, Salwen HR, Herst CV, Le Beau MM, Lee I, Bauer K, Marder RJ, Andersen R, Kies MS, et al. Establishment and characterization of a neuroendocrine skin carcinoma cell line. Lab Investig. 1987;56:302-12.

41. Guastafierro A, Feng H, Thant M, Kirkwood JM, Chang Y, Moore PS, Shuda M. Characterization of an early passage Merkel cell polyomavirus-positive Merkel cell carcinoma cell line, MS-1, and its growth in NOD scid gamma mice. J Virol Methods. 2013;187:6-14. https:/doi.org/10.1016/j.jviromet.2012.10.001.

42. Kwun HJ, Chang Y, Moore PS. Protein-mediated viral latency is a novel mechanism for Merkel cell polyomavirus persistence. Proc Natl Acad Sci U S A. 2017;114:e4040-7. https://doi.org/10.1073/pnas.1703879114.

43. Moens U, Krumbholz A, Ehlers B, Zell R, Johne R, Calvignac-Spencer S, Lauber C. Biology, evolution, and medical importance of polyomaviruses: an update. Infect Genet Evol. 2017;54:18-38. https://doi.org/10.1016/j.meegid. 2017.06.011.

44. Hashida Y, Imajoh M, Nemoto Y, Kamioka M, Taniguchi A, Taguchi T, Kume M, Orihashi K, Daibata M. Detection of Merkel cell polyomavirus with a tumour-specific signature in non-small cell lung cancer. Br J Cancer. 2013; 108:629-37. https://doi.org/10.1038/bjc.2012.567.

45. Pantulu ND, Pallasch CP, Kurz AK, Kassem A, Frenzel L, Sodenkamp S, Kvasnicka HM, Wendtner CM, Zur Hausen A. Detection of a novel truncating Merkel cell polyomavirus large T antigen deletion in chronic lymphocytic leukemia cells. Blood. 2010;1 16:5280-4. https://doi.org/10.1182/blood-2010-02-269829.

46. Velasquez C, Amako Y, Harold A, Toptan T, Chang Y, Shuda M. Characterization of a Merkel cell Polyomavirus-positive Merkel cell carcinoma cell line CVG-1. Front Microbiol. 2018;9:713. https://doi.org/10. 3389/fmicb.2018.00713.

\section{Publisher's Note}

Springer Nature remains neutral with regard to jurisdictional claims in published maps and institutional affiliations. 